\title{
As territorialidades de Empreendimentos Econômicos Solidários (EES) no contexto de um sistema produtivo do turismo: um estudo de caso em Corumbá (MS)
}

\author{
The territorialities of Solidarity Economic Enterprise (SEE) in the \\ context of tourism productive system: a case study in Corumbá \\ (MS, Brazil)
}

\author{
Milton Augusto Pasquotto Mariani, Rosa Maria Fischer
}

\section{RESUMO}

Este artigo tem como propósito revelar as territorialidades no seio de determinados empreendimentos, e a consequente dinâmica de inserção de organizações no âmbito de um sistema produtivo do turismo. Para tanto, empregou-se o estudo de caso da dinâmica de atuação de um grupo de empreendimentos econômicos solidários atuantes no turismo local e regional de Corumbá, no Mato Grosso do Sul. Parte-se da problemática de que as territorialidades exercidas pelos são aspectos que lhe conferem autenticidade, culminando - consequentemente - no incremento da atividade turística e na própria 'autenticidade' da prática do turismo local. Constatou-se, a partir da observação participante e entrevistas com os gestores, que os empreendimentos exercem territorialidades que lhes possibilitam uma inserção no sistema produtivo do turismo local, sobretudo por conta da valorização das tradições e elementos da cultura local, ligados ao Pantanal e ao homem pantaneiro; além da possibilidade de diversificação das atividades características do próprio sistema turístico local, pautado principalmente na pesca e na contemplação da natureza.

PALAVRAS-CHAVE: Territorialidades; Sistema Turístico; Empreendimentos Econômico Solidários.

\section{ABSTRACT}

This paper aims to reveal the territoriality within particular projects, and as a result of the process of insertion of these organizations within a tourism productive system. For this, we used a case study about the business of a group of Solidarity Economic Enterprises active in the local and regional tourism activity in Corumbá, in Mato Grosso do Sul, Brazil. The study is premised upon the problem that territoriality practiced by enterprises themselves consists of aspects that give them authenticity, culminating - consequently - in the increase of the tourism activity and in the 'authenticity' itself of the practice of local tourism. It was shown, from participant observation and interviews with managers, that enterprises perform territoriality that enable them to insert in the local tourism productive system, mainly due to the increase of the value of the traditions and elements of local culture, linked to the Pantanal and the man from Pantanal; beyond the possibility of diversification of characteristic activities of the local tourism system itself, based primarily on fishing and contemplation of nature.

KEYWORDS: Territoriality; Touristic System; Solidarity Economic Enterprise. 


\section{Introdução}

A atividade turística, na medida em que é submetida a uma análise de caráter mais holístico e criterioso, pode ser entendida como um fenômeno cultural, social, ecológico e econômico, gerador de novas experiências no instante em que o seu praticante se depara com cenários e paisagens não habituais e olha, interessado e curioso, o ambiente que o cerca. Representa um afastamento, uma ruptura limitada com rotinas e práticas bem estabelecidas da vida de todos os dias, permitindo que os sentidos se abram para um conjunto de estímulos contrastantes entre o cotidiano e o mundano (URRY, 2001).

O turismo é notadamente um segmento com importante impacto socioeconômico no mundo todo. Dados do World Travel and Tourism Council (WTCC, 2012a) dão conta de que o setor de viagens e turismo, em 2011, contribuiu com 9\% de todo o montante de Produto Interno Bruto (PIB) mundial, o que perfaz seis trilhões de dólares em valores monetários, e mais de 225 milhões de empregos diretos e indiretos.

No Brasil, a contribuição econômica do setor de viagens e turismo no ano de 2011 foi de $8,6 \%$ de todo o PIB nacional, representando algo como $\mathrm{R} \$ 356$ bilhões, a preços constantes. A geração de empregos diretos e indiretos nesse setor, no mesmo período em tela, foi de pouco mais de 7,6 milhões de postos de trabalho (perfazendo 7,8\% do total de empregos diretos e indiretos no país) (WTCC, 2012b).

O comportamento e o perfil do turista contemporâneo estão intrinsecamente relacionados com alguns fenômenos recentes, tais como o individualismo exacerbado, a intensidade da urbanização e industrialização dos espaços, além de mudanças nas condições de trabalho (CASTRO, 2001). Tais aspectos, associados à necessidade de 'fuga' dos grandes centros urbanos e à consequente (re)valorização dos espaços naturais, têm provocado uma guinada da prática do turismo rumo à atividades e experiências consideradas típicas e únicas, especialmente quando há a conformação do 'singular' com o 'natural' (THOMAZ; MARIANI; MORETTI, 2012).

A necessidade das comunidades passarem a interferir em seu próprio crescimento, em busca de maior dinamismo nas atividades econômicas locais, e de lutarem por melhores condições de geração de renda e de distribuição de riqueza, impuseram-se, fazendo emergir um conjunto de iniciativas empreendedoras. Configura-se, assim, um quadro inovador que pode ser classificado no âmbito do conceito de desenvolvimento sustentável, o qual se caracteriza pela constituição de dinâmicas sociais onde os indivíduos organizam-se em prol de seus objetivos mais urgentes, como a criação de novas oportunidades de trabalho; ou a manutenção e regulação do emprego das especificidades socioambientais dos locais onde residem; além da garantia dos seus próprios direitos de cidadania.

Destaca-se nesse cenário não apenas a ampliação das oportunidades de crescimento econômico e de mudança social, como também, a sustentabilidade assegurada pela valorização dos recursos humanos, culturais, históricos e naturais que constituem o patrimônio de uma comunidade (FISCHER; COMINI, 2012). 
Nesta linha de reflexões, as próprias pessoas e comunidades, podem ofertar produtos turísticos que representam - através da (re)valorização de sua cultura, tradições, ritos e de seu espaço habitado - aspectos que exerçam atratividade e o consequente desejo dos turistas de virem a conhecer essas especificidades e dinâmicas.

As territorialidades podem ser definidas como a síntese das relações sociais que dão corpo e conferem função ao território - este último entendido como um substrato construído a partir das relações humanas, seja numa conotação material ou imaterial. Numa abordagem introdutória, pode-se dizer que as territorialidades são a 'razão de ser' dos territórios, conferindo-Ihe existência, de forma essencialmente física, ou mesmo imaterial (SACK, 1986; SOUZA, 2009; HAESBAERT, 2004).

Os Empreendimentos Econômicos Solidários (EES), entendidos como formas organizacionais calcadas na produção de bens/serviços através de princípios majoritariamente relacionados à solidariedade e autogestão, são exemplos de espaços onde a cultura e as tradições de um povo, portanto, suas territorialidades podem ser manifestadas, exercendo atratividade necessária para a oferta de produtos e serviços próprios do sistema produtivo do turismo (ARRUDA, 2011).

É neste âmbito teórico e conceitual que se encontra a pesquisa que ilustra este artigo. Esse trabalho teve como objetivo geral revelar as territorialidades no seio de determinados EES, e a consequente dinâmica de inserção destas organizações no âmbito de um sistema produtivo do turismo. Para tanto, empregou-se o estudo de caso da dinâmica de atuação de um grupo de EES atuantes no turismo local e regional de Corumbá, no Mato Grosso do Sul.

Em suma, parte-se da problemática de que as territorialidades exercidas pelos próprios EES são aspectos que lhe conferem autenticidade, culminando - consequentemente - no incremento da atividade turística e na própria 'autenticidade' da prática do turismo local.

\section{Território}

O estudo do território vem se constituindo em um eixo predominante do pensamento geográfico nos últimos 100 anos (VALVERDE, 2004). Instintivamente, o seu conceito remonta à idéia de lugar, espaço de residência, ou local de inserção, no qual se desenrolam as múltiplas relações entre os agentes sociais e econômicos. Muito embora esta seja uma definição que suprime os elementos norteadores do conceito de território, ela não é de todo errada. Pode ser considerada incompleta para a realidade atual.

Até meados do século $X X$, diante das constantes disputas por mercados consumidores pelos países capitalistas desenvolvidos, sobretudo no chamado "Terceiro Mundo", o conceito de território confundia-se com a noção de Estado-Nação. Nesta perspectiva, os territórios eram inteiriços, limitados apenas pelas fronteiras físicas com outros países e geridos por um poder político estatal, que promovia as políticas de bem-estar e segurança nacional, garantindo a legitimidade do espaço territorial sob seu domínio. 
Porém, nos últimos 20 anos, em função das mudanças sociais, econômicas e políticas que modificaram o desenho geopolítico e as relações sociais e econômicas o conceito de território ganhou um sentido diferente, mais amplo, para abordar uma infinidade de questões pertinentes ao controle físico ou simbólico de determinada área (VALVERDE, 2004). O fenômeno de globalização, que provocou o surgimento de empresas multinacionais/transnacionais e a intensificação da frequência das relações e interações dos múltiplos territórios em rede, minou o poder político dos Estados-Nação, conferindo ao conceito de território um sentido mais plural, recoberto de maior complexidade.

Portanto, migra-se de uma concepção vertical dominante no início do século $X X$, onde os territórios eram fortes e vitoriosos em decorrência de sua extensão material, para uma concepção horizontal oriunda do processo de globalização, que enfatiza a característica de abrangência das relações de poder dos agentes, independentemente, da contigüidade ou não dos espaços físicos ocupados.

Assim sendo, o território passa de uma conotação essencialmente material, palpável, representada pela conjunção do solo e de seu povo (RATZEL, 1988); para uma conotação imaterial, intangível, definida pelas relações de poder. Estas podem ser criadas e se desfazer ciclicamente, ter duração efêmera ou, nem mesmo, chegar a deixar marcas na paisagem, o que descaracteriza a materialidade dos territórios (SOUZA, 2009).

Há múltiplas abordagens sobre as concepções de território e as formas como ele é interpretado nas ciências sociais, o que sugere a existência de uma diversidade de enfoques. Não obstante, em qualquer acepção, o território tem a ver com poder, mas não apenas ao tradicional "poder político" que remete ao jogo partidário próprio de cada sistema. Ele diz respeito tanto ao poder no sentido mais explícito, de dominação, quanto no sentido mais implícito ou simbólico, de apropriação (HAESBAERT, 2007).

Conceitualmente, tal poder de dominação diz respeito à posse ou propriedade dos territórios, numa conotação de estabelecimento de força (seja militar, política ou de outra ordem) para o controle dos territórios. Já o poder de apropriação representa um processo muito mais subjetivo, carregado de marcas do "vivido" e do valor de uso dos territórios e suas manifestações culturais peculiares (LEFEBVRE, 1986). Assim, o território, imerso em relações de dominação e/ou de apropriação, "desdobra-se ao longo de um continuum que vai da dominação político-econômica mais 'concreta' e 'funcional' à apropriação mais subjetiva e/ou 'cultural-simbólica"' (HAESBAERT, 2004).

Muito embora o poder de apropriação devesse sobrepujar o poder de dominação (LEFEBVRE, 1986), de modo que os territórios efetivamente se constituíssem em espaços de alteridade e expressões dos grupos sociais, observa-se que a dinâmica da acumulação capitalista fez com que a dominação prevalecesse sobre a apropriação. O que confere aos territórios a característica de mercadoria, isto passível de transações mercantis.

Rogério Haesbaert, um dos mais importantes pesquisadores das temáticas territoriais brasileiras, considera que o território, uma vez 
expressando o local da manifestação de poder, apresenta três perspectivas distintas: jurídico-política, cultural e econômica (HAESBAERT, 2001). Na perspectiva jurídico-política, o território é visto como um espaço delimitado e controlado sobre o qual se exerce um determinado poder, especialmente o de caráter estatal. $\mathrm{Na}$ perspectiva cultural prioriza-se as dimensões simbólicas e mais subjetivas, onde o território é visto, fundamentalmente, como produto da apropriação feita através do imaginário e/ou da identidade social sobre o espaço. E, por fim, na perspectiva econômica, na qual se destaca o território como produto espacial do embate entre classes sociais e da relação capital-trabalho (HAESBAERT apud SPOSITO, 2004, p.18).

Assim sendo, ressalta-se que o fator diferenciador da definição de território são as relações de poder que lhe dão corpo, bem como as manifestações culturais dos agentes que habitam em seu espaço físico. $O$ território se forma a partir do espaço, é o resultado de uma ação conduzida por um ator que realiza um programa em qualquer nível. Ao se apropriar de um espaço, concreta ou abstratamente, o ator "territorializa" o espaço (RAFFESTIN, 1993).

Desta feita, o território é uma categoria de análise produzida por ações políticas e socioeconômicas. Emerge como um produto da construção de uma sociedade, num processo de apropriação de uma porção do espaço por uma coletividade. Esta categoria de análise pode ser abordada sob uma perspectiva simbólica, onde as pessoas, enquanto agentes sociais, econômicos e políticos expressam sua existência através de formas intimamente ligadas ao território.

\section{Territorialidades}

A territorialidade - muito embora pareça um conceito novo ao leitor pouco familiarizado com o termo - representa uma práxis que não é recente, qual seja: a organização do espaço geográfico em esferas de influência, sobretudo, através das ações dos atores sociais que, uma vez organizados, 'emprestam' sua identidade, sua cultura e seus interesses aos espaços físicos por eles ocupados.

Sobre este aspecto, Silva (2002) pontua que a territorialidade associa-se fundamentalmente ao comportamento das pessoas e das organizações. Ademais, afirma que, a territorialidade resume-se na base de poder de determinado grupo sobre certo tipo de espaço geográfico, ou seja: trata-se de uma estratégia para afetar, influenciar ou controlar recursos e pessoas pertencentes a um determinado território.

A territorialidade, deste modo, reveste-se de uma dimensão política. Não obstante, tipifica-se também por relações econômicas e culturais, já que está "(...) intimamente ligada ao modo como as pessoas utilizam a terra, como elas próprias se organizam no espaço e como elas dão significado ao lugar" (SACK, 1986, p. 219).

Segundo Soja apud Raffestin (1993, p.162), a territorialidade é composta por três elementos: senso de identidade espacial; senso de exclusividade; e compartimentação da interação humana no espaço. Sua 
função é a manutenção do território, ou seja, sua defesa, garantindo uma espécie de equilíbrio entre as sociedades e a natureza.

A formação do território dá às pessoas que nele habitam a consciência de sua participação, provocando o sentimento de territorialidade, que de forma subjetiva cria uma consciência de confraternização entre as mesmas (ANDRADE, 1998; MOINE, 2006; MORVAN, 1985). Entende-se, nesse sentido, que a própria prevalência de um sentimento de solidariedade entre os indivíduos constitui uma territorialidade.

Da mesma forma que os territórios podem ser materiais ou imateriais de acordo com as construções que os indivíduos lhe conferem, as territorialidades também podem expressar-se como materialidade, imaterialidade ou como espaço vivido, dependendo do conceito de território proposto (HAESBAERT, 2007).

A territorialidade como materialidade, como o próprio termo sugere, é aquela que se expressa nos territórios materiais, que são aqueles com substrato físico, conforme sugere o termo. Pode-se dizer que ela tem como função a delimitação e consequente configuração física dos territórios, e confere a dominação dos mesmos aos grupos. Neste caso, tais grupos dominantes controlam o acesso de outros grupos aos territórios, muito embora os mesmos territórios tenham funções meramente funcionais, sem marcas simbólicas e/ou culturais dos indivíduos.

No que tange à territorialidade como imaterialidade, observa-se que a tônica da configuração dos territórios são as marcas simbólicas e culturais dos indivíduos para com o território, sendo que este pode ser material ou imaterial. No caso dos territórios imateriais, eles são meras construções do imaginário dos grupos, que mesmo assim exercem suas territorialidades para com o espaço.

Portanto, deve-se ter consolidada a ideia de que as territorialidades, de uma forma geral, uma vez representando a síntese das relações de poder que se estabelecem nos territórios, são os elementos que the conferem suas configurações, mesmo que tais territorialidades sejam expressas como materialidade, imaterialidade ou como espaço vivido.

Porém, aqui surge uma questão, dado o escopo do presente trabalho: de que forma as territorialidades associam-se propriamente à gênese e organização de sistemas turísticos? Para este questionamento, Arruda (2013) fornece interessantes subsídios analíticos, na medida em que pontua que as territorialidades (e, consequentemente, a própria configuração territorial) influenciam nas dinâmicas de coordenação e nas estruturas de governança presentes em sistemas turísticos, minimizando custos de transação entre os agentes econômicos e, por conseguinte, maximizando a eficiência da própria atividade turística de base local e territorial ${ }^{1}$.

Não obstante, o argumento subjacente ao presente trabalho é de que as territorialidades, a despeito de suas implicações de cunho estritamente econômico e organizacional, são aspectos que conferem autenticidade às práticas de turismo, exercendo atratividade para os visitantes. Sendo assim, as relações sociais, a cultura, e até a (re)valorização do imaginário imanente 
à 'ocupação' dos territórios representam territorialidades que conferem particularidade a este mesmo território e nutrem estreita relação com 0 planejamento e a prática do turismo.

O território apropriado e o capital social que lhe é intrínseco facilitam o compartilhamento de informações entre os atores sociais, permitindo assim a melhor coordenação das ações e a estabilidade institucional e organizacional, o que concorre, mesmo que de forma indireta, para a eficiência dos sistemas econômicos nele sediados (VILPOUX; OLIVEIRA, 2010).

Muls (2008) salienta que significativa parcela das relações entre os agentes econômicos estão descoladas das relações essencialmente mercantis, de tal modo que a cultura, símbolos e regras das mais distintas comunidades e territórios possuem salutar relevância.

Dentre as organizações que expressam suas territorialidades de forma não raro estritamente calcada no turismo estão os Empreendimentos Econômicos Solidários (EES) que - com base nos princípios de igualdade, solidariedade, reciprocidade, democracia e autogestão - tipificam e particularizam os territórios nos quais estão inseridos e, nesta dinâmica, podem fomentar o turismo e conferir maior dinamismo e desenvolvimento ao território.

\section{Economia solidária no contexto de Empreendimentos Econômicos Solidários}

As características específicas das organizações estudas - no caso Empreendimentos Econômicos Solidários - demandam que neste texto se faça uma breve abordagem do conceito e das práticas da chamada Economia Solidária. Pode-se considerá-la como uma corrente de pensamento que surge em um contexto de baixa taxa de ocupação da população economicamente ativa, má qualidade dos empregos oferecidos e carência de proteção social dos trabalhadores assalariados. Ela se caracteriza por preconizar ações socioeconômicas que procuram superar esses desafios através da criação de oportunidades de geração de renda criadas e administradas pelos próprios trabalhadores.

Trata-se de ações fundamentadas em uma lógica que objetiva evitar a alienação do trabalho e assegurar o bem-estar dos trabalhadores, organizados sob a forma de cooperativas ou associações socioprodutivas, as quais se orientam por princípios basilares, tais como: a autogestão administrativa; a solidariedade organizativa; a democracia no processo decisório e nos critérios de repartição das sobras. São princípios que visam garantir a autonomia decisória e a plenitude na efetivação do trabalho como instrumento de emanação da criatividade e da cultura dos agentes envolvidos nos processos socioprodutivos.

Nota-se que a economia solidária, do modo como foi sinteticamente descrita, orienta-se como uma reação natural às forças excludentes do sistema capitalista, sobretudo, aquelas que resultam em alienação e precarização do trabalho assalariado. Alguns autores, principalmente aqueles partidários das análises dos movimentos sociais, interpretam a 
economia solidária como um novo modo de produção, passível de uma abordagem revolucionária de superação dos desígnios acumulativos/excludentes inerentes ao sistema capitalista. Outros teóricos, mais alinhados à discussão instrumental da economia solidária, a tipificam como um mecanismo de política pública; ou como a síntese de ações que visam à inserção social ativa dos indivíduos/trabalhadores no capitalismo, numa clara demonstração de 'humanização' do sistema capitalista e, por conseguinte, da economia.

Sendo assim, ao se remeter a economia solidária à perspectiva analítica do desenvolvimento socioeconômico de base local, o qual, por sua vez, está inserido no quadro conceitual do Desenvolvimento Sustentável, preceitua-se que os Empreendimentos Econômicos Solidários (EES) devem ter na comunidade a gênese de suas ações; bem como, devem considerar esta mesma comunidade como a beneficiária de tais ações.

Entende-se que o termo comunidade designa um grupo de indivíduos estabelecidos em uma dada localidade, que apresentam laços de identidade entre si e com o ambiente onde residem. Ander-Egg (1980, p.45) lança luz sobre essa questão ao definir comunidade como:

(...) um agrupamento organizado de pessoas que se percebem como unidade social, participam dos mesmos interesses, objetivos e funções comuns, com consciência de pertencimento, situados em uma determinada área geográfica, na qual há pluralidade de pessoas que interagem mais intensamente entre si, que em outro contexto.

Desta feita, a comunidade é o local onde se evidenciam a intensidade e o grau de afinidade dos atores, de modo que representa um contraste às formas desiguais de apropriação da riqueza, distribuída majoritariamente para os grupos minoritários que são detentores do capital.

Souza (2008, p.55) ao analisar os modos como as iniciativas de economia solidária são substantivadas, considera que os Empreendimentos de Economia Solidária (EES) ${ }^{2}$ tipificam-se por uma miríade de relações socioeconômicas, "(...) organizadas sob a forma de cooperativas, associações, empresas autogestionárias, redes de cooperação, complexos cooperativos, entre outras, que realizam atividades de produção de bens, prestação de serviços, finanças, trocas, comércio e consumo". Esta diversidade de formatos organizacionais e jurídicos, ao mesmo tempo em que colabora para facilitar aos empreendedores a concretização de seu desejo de autonomia, constitui um desafio à pesquisa porque dificulta a identificação de padrões, a análise das características e a verificação do desempenho.

Contudo, pode-se ressaltar algumas características comuns a tais empreendimentos: eles retomam a unicidade do processo produtivo, onde os indivíduos organizados são os proprietários dos meios de produção; promovem a 'socialização' desses meios de produção através da propriedade coletiva; e remuneram o trabalho cooperado, de forma justa. Tais características fortalecem o "pertencimento" à comunidade, o que 
permite inferir que contribuem para a fixação das pessoas ao território, com a consequente valorização de seus ativos sociais (OSTROM, 1999).

Dentro da dinâmica ora exposta, as iniciativas calcadas nos EES não devem ser confundidas com meras formas de assistencialismo para com os ditos 'excluídos do sistema' (SINGER, 2006). Tais empreendimentos devem incitar as comunidades locais a buscarem soluções para o seu dia a dia de forma coletiva; a se preocupar em estimular o convívio social; além de fomentar a solidariedade (MANCE, 2002).

No Brasil em específico, as discussões teóricas acerca da economia solidária iniciaram-se na década de 1980, mas é nos idos de 1990 que ganha corpo em face da emergência de iniciativas empreendidas por pessoas e grupos 'excluídos do sistema', em função da desigualdade socioeconômica. Em 2003, o fomento a EES ganhou status de política governamental em virtude da criação da Secretaria Nacional de Economia Solidária (SENAES), subordinada ao Ministério do Trabalho e Emprego (MTE). No âmbito acadêmico, surge também relativo engajamento, através de mobilizações e discussões acerca da temática em voga, principalmente, após a implementação da Rede Universitária de Incubadoras Tecnológicas de Cooperativas Populares - Rede Universitária de ITCPs (FRANÇA FILHO et al., 2006).

No âmbito prático, mais uma vez vale pontuar que os projetos de economia solidária são vistos rotineiramente sob a forma de cooperativas (sejam elas de produção, trocas ou consumo), associações e núcleos/grupos de produção e comercialização que, além de buscarem atender aos anseios econômicos de seu público-alvo, cumprem a finalidade de atender às 'necessidades humanas' dos mesmos. Estão nesta categoria a socialização dos recursos disponíveis, o respeito à igualdade de cada um e entre todos, bem como, o emprego de métodos democráticos nos processos decisórios. Nesse sentido, diz-se que a lógica das iniciativas de economia solidária é a promoção do 'bem-viver' das pessoas, configurando que, mais do que apenas uma proposta de organização da produção, ela se pretende uma filosofia da vida coletiva.

Com base em Coriolano (2008) pode-se depreender que os EES podem conformar-se, a depender dos locais onde estão inseridos, no chamado turismo comunitário de base local. Considera-se que este tipo de turismo, como o próprio termo sugere, tipifica-se pela associação de indivíduos residentes em um mesmo território e com algum laço de identidade entre si (daí a ideia de comunidade), sob a forma de sistemas produtivos locais, de tal modo que o controle da oferta dos aparatos do turismo desenvolvido no território em questão é detido pela própria comunidade (SAMPAIO, 2005).

\section{Procedimentos metodológicos}

As reflexões deste trabalho são decorrentes da análise dos dados oriundos do projeto de pesquisa/extensão intitulado "Incubação de Empreendimentos Econômicos Solidários na Cadeia Produtiva do Turismo nas Regiões de Bonito e Serra da Bodoquena e do Pantanal/Corumbá". Este projeto insere-se no escopo da Economia Solidária voltado ao 
incremento atividade turística em territórios sul-mato-grossenses, tendo o apoio da Financiadora de Estudos e Projetos do Ministério da Ciência e Tecnologia (FINEP/MCT) e do Ministério do Turismo (MTUR). Sua vertente acadêmica foi executada pelo consórcio formado pelas: Universidade Federal de Mato Grosso do Sul (UFMS), Universidade Federal da Grande Dourados (UFGD), Universidade Católica Dom Bosco (UCDB) e Universidade Estadual de Mato Grosso do Sul (UEMS).

Para alcançar os objetivos propostos na pesquisa sobre o funcionamento das EES estudadas, foram realizados levantamentos de dados primários em campo através de entrevistas semi estruturadas e roteiros de observação sistematizada. Os dados secundários foram obtidos em fontes oficiais para contextualizar a situação empírica estudada.

Quanto aos fins delineados, a pesquisa realizada pode ser classificada como sendo uma pesquisa exploratória e descritiva, de caráter qualitativo. Vergara (2005) salienta que a pesquisa exploratória cumpre o fim de analisar, in loco, os atores-chave para a elucidação do tema; ao passo que a pesquisa descritiva elucida as características do fenômeno observado.

Em face aos meios utilizados, considera-se que a pesquisa se classifica como um estudo de caso. Rememorando as considerações de Yin (2005, p.32), um estudo de caso constitui-se em "(...) uma investigação empírica que investiga um fenômeno dentro de seu contexto da vida real, especialmente quando os limites entre o fenômeno e o contexto não estão claramente definidos".

Foram selecionados para a pesquisa de campo quatro EES no território de Corumbá, quais sejam: o núcleo de corte/costura do Instituto Homem Pantaneiro; o núcleo de gastronomia do mesmo Instituto; a Associação de Mulheres Organizadas Reciclando o Peixe (Amorpeixe); além da Associação Não-governamental Casa do Massabarro. Foram feitas 20 entrevistas, sendo 16 entrevistados participantes dos empreendimentos e 04 gestores.

A escolha dos EES visitados foi intencional, obedecendo-se os critérios de pertinência, levando-se em conta as características dessas organizações no que concerne às suas missões e suas inserções no sistema do turismo. Considerou-se também as possibilidades técnicas de se realizar o levantamento empírico, bem como a disponibilidade dos gestores em participar do processo de pesquisa.

Dentre os tópicos constantes nas entrevistas semi estruturadas e nos roteiros de observação destacam-se: as questões referentes às características estruturais dos EES (como: o tempo de existência dos empreendimentos; número de participantes; ações desencadeadas pelos grupos), as indagações referentes ao perfil dos integrantes dos EES (como: idade; grau de escolaridade); além do levantamento das opiniões e percepções destes sujeitos quanto aos seus empreendimentos, à sua comunidade e às possibilidades do sistema de turismo local. 


\section{Resultados e discussões}

\section{Corumbá e o sistema turístico local}

O município de Corumbá é o mais importante pólo urbano e econômico da chamada Região Fronteiriça de Corumbá, que abrange também o município de Ladário, no Estado de Mato Grosso do Sul; além das seções municipais de Porto Suárez e Porto Quijarro, no Departamento de Santa Cruz, na Bolívia. Corumbá possui uma população absoluta próxima dos 104 mil habitantes, distribuídos em uma área total de quase 65 mil $\mathrm{km}^{2}$. Os biomas predominantes na região são o cerrado e pantanal; ao passo que as principais atividades econômicas locais resumem-se à pecuária de corte, ao extrativismo mineral, ao turismo e ao comércio interfronteiriço.

Do total dos 104 mil habitantes no município, 82\% perfaz a População em Idade Ativa (PIA) do município - que são aqueles indivíduos com 10 anos de idade ou mais, teoricamente aptos a exercer alguma atividade econômica. Não obstante, do total da PIA, 57\% representam os indivíduos que estão ocupados (seja formal ou informalmente); bem como aqueles que estão desempregados, considerando os dados do Censo Demográfico de 2010 realizado pelo IBGE (2012).

Os indivíduos que se declararam desempregados à época da realização do Censo, nota-se um quantitativo próximo de $8 \%$ da População Economicamente Ativa (PEA) de Corumbá - o que representa um indicador de taxa de ocupação muito próximo à índices de pleno emprego, conforme se pode observar em Proni (2012) e Mediaas (2012).

Numa primeira análise, estes indicadores relativos às taxas de ocupação em Corumbá proporcionam o levantamento de questões não raro conflitantes às análises de Singer (2002 e 2006), que situa o surgimento e consolidação do movimento de economia solidária em um contexto de desocupação dos trabalhadores. Porém, ao se analisar alguns aspectos qualitativos das conjunturas do mercado de trabalho em Corumbá, surgem indícios, que certamente atestam a importância do movimento de economia solidária local na região fronteiriça em tela.

Do total da PEA corumbaense, ainda segundo dados do IBGE (2012), algo em torno de 26 mil indivíduos é constituído por pessoas que se autodeclararam desempregados; empregados sem carteira de trabalho assinada; empreendedores autônomos; trabalhadores não remunerados; além de trabalhadores na produção para o consumo próprio. Este número perfaz, notadamente, $54 \%$ da PEA de Corumbá; ou aproximadamente $25 \%$ de toda a população absoluta local.

Manetta (2009) e Manetta e Carmo (2011), corroborando os argumentos supracitados, reiteram que o município de Corumbá e toda a região fronteiriça em seu entorno - muito embora tenham logrado uma significativa expansão de sua importância econômica sobretudo no correr da década de 1990 - não foram capazes de gerar oportunidades duradouras e condizentes de trabalho e de obtenção de renda para significativa parte da população concorrendo para o acirramento do fluxo migratório na região. 
A atividade turística, principalmente no que se refere ao turismo de pesca, é uma importante fonte de renda para o município. Segundo dados do Sistema de Controle da Pesca de Mato Grosso do Sul temos que:

\begin{abstract}
Os pescadores esportivos vieram principalmente dos estados de São Paulo (50,8\%), Paraná (19,4\%) e Minas Gerais $(8,4 \%)$, utilizando, sobretudo meio de transporte rodoviário, por meio de veículo próprio $(51,9 \%)$ ou de ônibus $(39,9 \%)$. Cerca de $(7,8 \%)$ dos pescadores esportivos utilizaram avião (1.111), em sua maioria com destino a Corumbá (1.021) (SCPESCA/MS 17, 2010).
\end{abstract}

Analisando a distribuição da renda advinda do turismo de pesca no município, Arruda et al. (2013, p.10-11), identificam dois mercados de turismo existentes no município e os diferenciam a partir da origem dos indivíduos. Segundo os autores, o turista local/ regional acaba por utilizar-se das amenidades disponíveis na cidade, tais quais, os hotéis e atrativos turísticos, consumindo produtos de diversos agentes do sistema turístico do município, enquanto o turista nacional e internacional é geralmente voltado ao turismo de pesca e ao utilizar-se dos barcos-hotéis acaba por permanecer apenas um dia na cidade. Consumindo produtos de apenas um agente do sistema, gera a concentração de renda na mão de poucos empresários já estabelecidos e que, muitas vezes, não residem no município, nem mantém relações com os moradores locais.

Através das incursões no território estudado, observou-se a concentração das receitas do turismo nas mãos de poucos agentes que verticalizam o processo turístico e deixam à margem desse processo diversos atrativos culturais. Configura-se a falta de sinergia entre os agentes, o que acaba por limitar o desenvolvimento pleno das potencialidades turísticas do município.

Através das entrevistas realizadas pode-se verificar uma forte verticalização do sistema turístico local a partir do controle de um só grupo de todos os processos envolvidos no turismo. De forma costumeira, o dono da agência é proprietário de seu próprio barco pesqueiro, do hotel e assim por diante. Quando não, há a existência de acordos informais entre os agentes a fim de se obter vantagens no mercado de turismo local.

Assim, da maneira em que se encontra organizado, o turismo de pesca de Corumbá acaba por deixar pouco ou nenhum benefício para os cidadãos e empreendimentos locais, dentre eles os EES situados na cidade. É digno de nota também, que grande parte dos proprietários dos empreendimentos envolvidos na cadeia produtiva do turismo na região, em especial do turismo de pesca nem mesmo reside no município. 


\section{Os empreendimentos e suas territorialidades}

Quanto às características organizacionais dos EES analisados, constatou-se a existência de 02 associações; 01 cooperativa e 01 núcleo/grupo de produção. No que se refere à natureza das atividades dos EES, a maioria dos seus respectivos gestores alegou que o negócio destina-se às funções de produção de artefatos artesanais (67\% do total de citações), ao passo que o gestor de um único empreendimento relatou destinar-se às atividades de comercialização dos produtos $(16,5 \%$ das citações) e o de outro empreendimento disse voltar-se às atividades de produção, serviço e comércio (16,5\% das citações).

Resgatando alguns aspectos que motivaram a criação dos EES pesquisados, constatou-se que $43 \%$ das citações alegaram que os empreendimentos originaram-se por motivações de entidades sociais, seguidos de $29 \%$ que surgiram por conta de motivações familiares e/ou individuais, além de 14\% que começaram como alternativa de emprego e de outros $14 \%$ que representaram, em seu início, fonte complementar de renda aos integrantes.

Quanto aos integrantes dos EES, chegou-se à constatação de que a maioria é do sexo feminino, com faixa de idade de 30 a 50 anos. Ademais, são pessoas que, na maioria dos casos, apresentam ensino médio incompleto e pertencem ao mesmo tipo de negócio. Em todos os empreendimentos foi observado que os integrantes fizeram cursos profissionalizantes para exercerem a atividade, o que pode ter induzido melhoramentos na qualidade dos produtos, na opinião dos gestores dos negócios pesquisados.

Detendo-se um pouco mais no perfil desses indivíduos que personificam os EES, constatou-se que a maioria deles, expressos por $59 \%$ do total pesquisado, só trabalham e não têm carteira assinada, dedicandose integralmente às atividades dos EES e esporadicamente ocupando outras atividades remuneradas temporárias como forma de complementação de renda. Não obstante, $12 \%$ dos indivíduos estudam e não tem carteira assinada, de modo que, para esse público, os EES surgem como alternativa de ocupação e renda. Ademais, outros $12 \%$ trabalham em atividades com carteira assinada e $6 \%$ estudam e trabalham com carteira assinada, de forma que, no que se refere a esses indivíduos, aferiu-se por meio de citações espontâneas que as atividades nos EES representam algo prazeroso; que lhes dão satisfação.

No que tange à caracterização dos empreendimentos estudados, $\mathrm{O}$ Instituto Homem Pantaneiro - IHP - é uma organização não-governamental, que tem como missão promover o desenvolvimento sustentável do pantanal por meio de ações que conservem os capitais natural, social, cultural e histórico. Para cumprir sua missão, o IHP promove ações nas áreas de desenvolvimento sócio-cultural; histórico-cultural; meio ambiente e desenvolvimento de base, com o auxílio técnico e financeiro da mineradora VALE S.A, do Ministério da Cultura, da Orquestra Sinfônica Brasileira, e demais parceiros em projetos específicos.

Dentro do programa de desenvolvimento sócio-cultural do IHP foi criada, em 2005, a escola de artes Moinho Cultural Sul-Americano, que tem 
como escopo fornecer à crianças brasileiras e bolivianas aulas de dança, música e línguas. Ao final de 8 anos, que é o ciclo pedagógico estipulado, os participantes do projeto são considerados bailarinos ou musicistas, uma vez que recebem o devido certificado comprobatório das atividades que desenvolveram. Assim sendo, o projeto, além de fornecer base cultural aos participantes, contribui para sua profissionalização, de modo que tenham condições para gerarem sua própria renda.

Além disso, o IHP fomenta outros projetos, como o Vale Informática, que proporciona à comunidade aulas de informática e cidadania; o Ponto de Cultura, que fornece aulas de gastronomia, corte e costura para os indivíduos em geral; a Casa Brasil, que é um espaço comunitário que privilegia a formação e a capacitação em tecnologia aliada à cultura, arte, entretenimento e participação popular; além do projeto Ecodesenvolvimento, que contribui para o despertar de novas competências dos pescadores artesanais da cidade, de forma que os mesmos possam organizar-se e contribuir para a melhoria de sua situação econômica e social.

Já a Associação de Mulheres Organizadas Reciclando o Peixe (Amor-Peixe) é uma organização social e ambiental, fundada em 2003, que produz artesanato em couro de peixe a partir do aproveitamento do pescado. Há, nesse ínterim, parcerias com o grupo de pescadores artesanais da localidade, que fornecem o couro do peixe e demais subprodutos essenciais ao funcionamento da associação, que conta com 14 mulheres associadas, as quais são, a grande maioria, esposas de pescadores ou praticantes da atividade de pesca, diretamente.

Portanto, as territorialidades inerentes a atuação da Amor - Peixe expressa-se através da agregação de valor a um dos produtos tradicionais na região, que é o pescado, a partir da confecção de artesanatos a base de couro de peixe. Assim sendo, há a geração de renda econômica às mulheres associadas, em concomitância com a manutenção das características culturais locais.

Um aspecto peculiar da Amor-Peixe refere-se ao fato de que suas territorialidades não se limitam ao espaço de Corumbá. Face à divulgação dos produtos confeccionados para outras localidades, a associação territorializa novos espaços a partir de suas expressões culturais nos trabalhos artesanais, consolidando e expandindo seus territórios e, assim, suas características peculiares.

No que se refere à Associação Não-governamental Casa do Massabarro, ressalte-se que é uma entidade fundada em 1982 e que tem como escopo proporcionar às crianças do bairro Cervejaria, que é um local da cidade de Corumbá tipicamente habitado por pescadores e demais pessoas de baixa renda, um contato com a arte em cerâmica, de modo que possam dispor de alguma ocupação no período em que não estão na escola e, além disso, profissionalizar-se em algo que lhes possa gerar renda.

A Casa do Massabarro, como se pôde constatar através das observações sistematizadas durante a pesquisa, carece de melhor infraestrutura física para atender os garotos que participam do projeto, e, além disso, necessita implantar acompanhamento psico-pedagógico aos participantes, de modo a auxiliá-los nos seus anseios mais urgentes, 
cumprindo assim o fim social que a casa se destina a perseguir. Não obstante, dos projetos analisados, este é o que apresenta pouquíssimas parcerias para desenvolver suas ações, de modo que sustenta-se com a renda proveniente do artesanato fabricado e vendido.

As territorialidades inerentes a associação Casa do Massabarro, a despeito de suas deficiências estruturais, concorrem para a geração de renda econômica para pessoas em situação de vulnerabilidade socioeconômica através do artesanato, o que também fomenta as características culturais e expressões marcantes da localidade.

Um aspecto relevante das territorialidades expressas através das ações da Casa do Massabarro é que elas provocaram (ou ao menos tencionam provocar, considerando as deficiências estruturais que ainda existem) um processo de mudanças em um espaço historicamente territorializado pela criminalidade e demais mazelas sociais, como é o caso do bairro onde o projeto está instalado.

Por fim, o Projeto Social Ladrilho-Hidráulico é uma cooperativa que visa a fabricar ladrilhos artesanalmente, de modo que, com a venda dos materiais produzidos, há um incremento na renda dos cooperados. De tempos em tempos, há uma espécie de curso preparatório profissionalizante que tem como objetivo ministrar aulas à jovens de baixa renda da cidade de Corumbá e adjacências para inseri-los na prática de produção de ladrilhos artesanais.

O projeto recebe o apoio econômico-técnico do Instituto do Patrimônio Histórico e Artístico Nacional - IPHAN, que também demanda os materiais produzidos para que sejam utilizados, muitas vezes, em restaurações de prédios arquitetônicos antigos. Via de regra, os alunos que se identificarem com o curso preparatório são inseridos na cooperativa e já passam a trabalhar em prol da geração de renda mútua decorrente desta forma de organização.

As territorialidades inerentes ao Projeto Ladrilho Hidráulico destacamse pela manutenção e difusão dos aspectos culturais da região, além de constituir iniciativa de profissionalização e, assim, possível mecanismo de geração de renda para os indivíduos integrantes do empreendimento.

Observou-se que os EES característicos da cidade de Corumbá, por embasarem-se, em sua maioria, na produção de artefatos artesanais arraigados das especificidades culturais locais perfazem elementos que agregam percepções/sensações aos turistas que visitam a cidade, fomentando - indiretamente e, talvez, de forma incipiente - a atividade turística local.

Dada a proposta de ponderar a inserção dos EES na atividade do turismo em Corumbá, cumpre analisar, inicialmente, o nível de importância do turismo para o funcionamento dos empreendimentos investigados, vale dizer, identificar a intensidade dessa inserção. Sendo assim, na opinião de 03 gestores pesquisados o turismo exerce importância muito alta para 0 funcionamento do empreendimento; ao passo que, dos 02 gestores restantes, um alegou que tal importância é regular e outro considerou nula essa importância. 
Porém, muito embora existam gestores que considerem o turismo como sendo detentor de importância intermediária e/ou nula, constatou-se que a maioria deles - 03 dos gestores dos EES analisados, ou seja, $80 \%$ do total - pondera que é viável (na perspectiva dos EES) inserir-se na atividade turística local, sobretudo pela possibilidade de auferir maiores rendas; bem como, pela divulgação dos seus respectivos trabalhos artísticos junto aos turistas que visitam a região.

Na perspectiva dos integrantes dos EES, constatou-se a prevalência de uma relação harmoniosa com a prática da atividade turística, já que todos os sujeitos ouvidos alegaram que gostariam de ter pessoas de fora visitando a cidade. Ademais, corroborando tal percepção, aferiu-se que $94 \%$ dos entrevistados consideram que não há nenhum momento do ano em que os turistas incomodam os moradores locais, por conta das inúmeras práticas turísticas ali realizadas.

Ainda na perspectiva desses sujeitos, nota-se interesse em inserir-se na dinâmica da oferta de atrativos turísticos locais. Uma vez indagados se trabalhariam aos fins de semana nas atividades dos EES em funções relacionadas ao turismo local, por exemplo, caso isso lhes trouxesse algum ganho, notou-se que a totalidade dos sujeitos pesquisados externou opinião afirmativa.

No que tange à sustentabilidade de tal prática turística - entendida como as questões referentes à manutenção/preservação dos recursos naturais locais - percebe-se que gestores consideram que os EES exercem papel deveras relevante, pois os produtos artesanais de tais empreendimentos são provenientes da fauna e flora pantaneiras. Portanto, divulgam as características ambientais do território, o que naturalmente desperta a atenção do público, abrindo-se a possibilidade de que os turistas queiram conhecer tais recursos naturais e possam ser sensibilizados para a necessidade de preservar sua reprodução.

Dentre as propostas de fomento a tal desenvolvimento, ficam perceptíveis as dinâmicas de geração de renda econômica consubstanciadas à desalienação do trabalho dos indivíduos; bem como, à manutenção das especificidades socioculturais dos sujeitos envolvidos nos EES investigados. Ademais, vale reiterar as tônicas de preservação/manutenção dos recursos naturais locais preconizadas pela atuação dos integrantes dos EES que, por si só, também perfazem elementos de auxílio ao desenvolvimento local sob a perspectiva da sustentabilidade na gestão dos recursos naturais do território.

Porém, resta citar que, na prática, a inserção dos EES no turismo evidente em Corumbá não é substantivada do modo como as possibilidades são analisadas. Constatou-se que faltam, no município, um estreitamento das redes entre os stakeholders - como um todo - e os EES. Nesse sentido, prováveis rotas turísticas podem ser pensadas, inserindo-se os empreendimentos analisados na prática do turismo cultural e/ou gastronômico em Corumbá - só para citar alguns exemplos de rotas turísticas passiveis de serem implantadas e/ou fomentadas no território em questão. 
Nesta perspectiva de análise, indagados acerca da existência de parcerias com os stakeholders diretamente envolvido com o turismo em Corumbá (como lojas comerciais, redes hoteleiras ou outros negócios turísticos), notou-se que apenas em $33 \%$ dos empreendimentos visitados existe tal relação, sendo: 01 parceria com loja comercial e 01 parceria com uma ONG que se insere no roteiro turístico local. Nos $67 \%$ restantes, as parcerias restringem-se ao âmbito público, sobretudo no que tange aos programas assistenciais do governo e, desta feita, não nutrem relação direta com o turismo.

Os argumentos expostos, quando da breve caracterização das dinâmicas do movimento de economia solidária na cidade de Corumbá, sugerem que as territorialidades evidentes no âmbito da atuação dos EES associam-se à valorização da cultura do homem pantaneiro e do modo de vida no Pantanal, com sua religiosidade e consequente modo de interação com o meio ambiente.

Esses aspectos analisados relegam particularidade à organização dos produtos turísticos no âmbito do sistema produtivo do turismo local, de tal modo que o visitante que se desloca até Corumbá (em sua grande maioria motivada pelo turismo de pesca) tem a possibilidade de entrar em contato com a cultura local, através da interação com os EES e da aquisição dos bens/serviços por eles oferecidos.

\section{Considerações finais}

Como de praxe nas ciências sociais, não existem formulas conclusivas e interpretações irrefutáveis. No que tange às análises desta temática, não poderia ser diferente. Os territórios, cada qual dotados de territorialidades e demais potencialidade espaciais específicas, são elementos únicos, de modo que as dinâmicas de desenvolvimento devem tomá-los como critérios organizativos em separado.

As territorialidades perfazem importantes elementos que contribuem para a possível particularização da atividade turística, sobretudo por conta do caráter cultural e social característico das próprias territorialidades. No caso dos EES - dados os princípios de solidariedade, senso de comunidade e democracia, que Ihes são característicos - substantivam importantes territorialidades que podem concorrer, mais especificamente, para a singularização de produtos e práticas turísticas, no âmbito de sistemas produtivos do turismo.

Os EES investigados na cidade de Corumbá exercem territorialidades que Ihes possibilitam uma inserção - mesmo que precária - no sistema produtivo do turismo local, sobretudo por conta da valorização das tradições e elementos da cultura local, ligados ao Pantanal e ao homem pantaneiro; além da possibilidade de diversificação das atividades características do próprio sistema turístico em tela, tais como o turismo de pesca.

Não obstante, identificou-se que inexistem ações específicas do poder púbico e da iniciativa privada à inserção mais efetiva e ativa dos EES no sistema turístico local, o que indica uma oportunidade desperdiçada no 
âmbito da possibilidade (e necessidade) de diversificação da atividade turística em Corumbá.

Neste ínterim, sugere-se a elaboração de ações específicas à economia solidária voltada ao turismo em Corumbá. Uma possibilidade interessante seria a formatação de rotas turísticas entre os próprios EES, aliando também o próprio patrimônio arquitetônico local, com o escopo de ofertar novos produtos turísticos aos visitantes.

Vale ponderar que o presente estudo - muito embora indique importantes questões e implicações analíticas e empíricas - apresentou algumas limitações prementes, sobretudo no que tange ao tamanho da amostra pesquisada. Assim sendo, sugerem-se maiores investigações em outras realidades no Brasil, afim de que se descortinem as dinâmicas e especificidades dos EES e da própria gênese do turismo.

\section{Referências bibliográficas}

ANDER-EGG, E. Metodologia y Practica del Desarrollo de la Comunidad. 10ª edição. Tarragona: Editorial Universitária Européia, 1980.

ANDRADE, M.C. Territorialidades, desterritorialidades, novas territotialidades: os limites do poder nacional e o poder local. In: SANTOS, M.; SOUZA, M.A.A. e SILVEIRA, M.L. (Orgs). Território: globalização e fragmentação. São Paulo: Hucitec-ANPUR, 1998.

ARRUDA, D.O. MARIANI, M.A.P.; BITENCOURT, M.B.; SCHMIDT, V.; DIAS, D.T. La relación entre la economía solidaria y el desarrollo local: un estudio de caso volcado a los emprendimientos solidarios del turismo brasileño. Estudios y Perspectivas en Turismo, 2013.

ARRUDA, D.O. A Economia Solidária em Perspectiva: um estudo de caso acerca dos Empreendimentos Econômicos Solidários no território de Corumbá, no Mato Grosso do Sul. Monografia - Graduação em Ciências Econômicas. Universidade Federal de Mato Grosso do Sul - UFMS. Campo Grande: DEA/UFMS, 2011.

ARRUDA, D.O. Coordenação e Estruturas de Governança entre Agências de Turismo e Atrativos Turísticos em Bonito/MS. 2013. 125f. Dissertação (Mestrado em Administração) - Universidade Federal de Mato Grosso do Sul (UFMS), Campo Grande/MS, 2013.

ÁVILA, V.F. Realimentando discussão sobre teoria do desenvolvimento local (DL). Revista Interações (UCDB), Campo Grande/MS, vol. 08, no. 13, pp. 133-140, 2006.

CASTILHO, M.A.; MARIANI, M.A.P.; GARCIA, R.A.M. Economía solidaria y condiciones de autogestión en emprendimientos económicos solidarios en el municipio de Aquidauana (MS-Brasil). Revista Estudios y Perspectivas en Turismo, vol. 21, №. . 05, pp.1225-1243, 2012.

CASTRO, C. A natureza turística no Rio de Janeiro. In: BANDUCCI JR., A.; BARRETO, M. (Orgs). Turismo e identidade local: uma visão antropológica. Campinas/SP: Papirus, 2001. 
CORIOLANO, L.N.M.T. O turismo comunitário e a economia solidária no Ceará. In: II SEMINÁRIO INTERNACIONAL DE TURISMO SUSTENTÁVEL. Anais. Fortaleza/CE: UECE, 2008. 18p.

DUARTE, J.C.S. Territórios de identidade e multiterritorialidade, paradigmas para a formulação de uma nova regionalização da Bahia. In: V ENCONTRO DE ESTUDOS MULTIDISCIPLINAES EM CULTURA, Salvador, 2009. Anais. Salvador: UFBA, 2009.

FINEP - FINANCIADORA DE ESTUDOS E PROJETOS. IEESTUR Incubação de Empreendimentos Econômicos Solidários na Cadeia Produtiva do Turismo nas Regiões de Bonito/Serra da Bodoquena e do Pantanal/Corumbá. Relatório de Pesquisa. Rio de Janeiro, 2010.

FISCHER, R.M.; COMINI, G. Sustainable Development: from Responsibility to Entrepreneurship. Revista de Administração da USP - RAUSP, vol. 47, no 03, Jul-Set, 2012, pp. 363-369.

FÓRUM BRASILEIRO DE ECONOMIA SOLIDÁRIA - FBES. Sobre o FBES. 2011. Disponível em: <www.fbes.org.br>. Acesso em: 10 de abril de 2011.

FRANÇA FILHO, G.C.; LAVILLE, J.L.; MEDEIROS, A.; MAGNEN, J.F. (Orgs). Ação pública e economia solidária: uma perspectiva internacional. Porto Alegre: Editora da UFRGS, 2006.

HAESBAERT, R. Da desterritorialização à multiterritorialidade. In: X ENCONTRO DE GEÓGRAFOS DA AMÉRCIA LATINA, São Paulo, 2005. Anais. São Paulo: USP, 2005.

HAESBAERT, R. Le mythe de la déterritorialisation. Géographie et Cultures, Paris, vol. 40, p. 53-75, 2001.

HAESBAERT, R. O mito da desterritorialização: do "fim dos territórios" a multi-territorialidade. Rio de Janeiro: Bertrand Brasil, 2004.

HAESBAERT, R. Território e Multiterritorialidade: um debate. GEOgraphia, ano IX, no.17, p. 19-46, 2007.

INSTITUTO BRASILEIRO DE GEOGRAFIA E ESTATÍSTICA - IBGE. IBGE Cidades - Mato Grosso do Sul. 2012. Disponível em: $<$ http://www.ibge.gov.br/cidadesat>. Acesso em: 28 de setembro de 2012.

LEFEBVRE, H. La Production de L' Espace. Paris: Anthropos. 1986.

MANCE, E.A. Redes de colaboração solidária - aspetos econômicofilosóficos: complexidade e libertação. Petrópolis/RJ: Vozes, 2002.

MANETTA, A. Dinâmica populacional, urbanização e ambiente na região fronteiriça de Corumbá. 2009. Dissertação - Mestrado em Demografia. Instituto de Filosofia e Ciências Humanas, Universidade Estadual de Campinas. Campinas/SP: UNICAMP, 2009.

MANETTA, A.; CARMO, R.L. Integração socioeconômica e mobilidade espacial da população na região fronteiriça de Corumbá a partir da década de 1990. In: XIV Encontro Nacional da ANPUR. Anais. Rio de Janeiro/RJ: XIV ANPUR, 2011. 
MARIANI, M.A.P.; ARRUDA, D.O. A economia solidária como elemento fomentador do desenvolvimento local de Corumbá/MS/Brasil face à inserção dos pescadores artesanais na atividade do turismo. Pasos (EI Sauzal), vol. 09, ํo. 04, pp. 613-622, 2011.

MARIANI, M.A.P.; ARRUDA, D.O. Economia solidária, turismo e desenvolvimento local: breves reflexões aplicadas ao contexto de Corumbá, no Mato Grosso do Sul. In: 49o Congresso da SOBER. Anais. Belo Horizonte/MG: UFMG, 2011.

MARIANI, M.A.P.; ARRUDA, D.O.; AMARILIO, F.L. Pescadores Profissionais Urbanos de Corumbá/MS e suas Relações com a Atividade Turística Sustentável. Revista Brasileira de Ecoturismo, vol. 02, ㄲo․ 03, p. 205-238, 2009.

MEDIASS, L.M. Full employment must always be our main project. 2012. Policy Network, London, 18 de junho. Disponível em: <http://www.policy-network.net>. Acesso em: 28 de setembro de 2012.

MOINE, A. Le territoire comme un système complexe: un concept opératoire pour l'aménagement et la géographie. L'Espace Géographique, vol. 35, p. 115-132, 2006.

MORVAN, Y. Filière de production, in fondaments d'economie industrielle. Economica, p. 199-231, 1985.

MULS, L.M. Desenvolvimento local, espaço e território: o conceito de capital social e a importância de redes entre organismos e instituições locais. Revista Economia, Brasilia,vol.9, n. 01, p.1-21,2008.

OSTROM, E. Coping with tragedies of the commons. Annual Review of Political Science, vol. 02, June/1999, pp. 493-535.

PINTO, J.R.L. Economia Solidária: de volta à arte da associação. Porto Alegre: Editora da UFRGS, 2006.

PRONI, M.W. O debate sobre a tendência ao pleno emprego no Brasil. Revista Economia \& Tecnologia (RET), vol. 08, ํ‥ 02, pp.23-50, 2012.

RAFFESTIN, C. Por uma geografia do poder. São Paulo: Ática, 1993.

RATZEL, F. Géographie politique. Paris: Économica, 1988. 385 p.

SACK, R. Human Territoriality: its theory and history. Cambridge: Cambridge University Press, 1986.

SAMPAIO, C.A.C. Turismo como fenômeno humano: princípios para se pensar a socioeconomia. Rio Grande do Sul: Ed. EDUNISC, 2005.

SECPESCA/MS. Instituto de Meio Ambiente Pantanal - Governo do Estado de Mato Grosso do Sul. Relatório Anual. 2007

SENAES/MTE. Sistema Nacional de Informações em Economia Solidária Relatório Nacional. 2007.23 Disponível em: $<$ http://www.mte.gov.br/ecosolidaria/sies $>$. Acesso em: 23 de abril de 2011. 
SILVA. J.C. O conceito de Território na Geografia e a Territorialidade da Prostituição. In: RIBEIRO, M.A. (Org). Território e Prostituição na Metrópole Carioca. Rio de Janeiro: Ecomuseu Fluminense, 2002.

SINGER, P. Introdução à economia solidária. São Paulo/SP: Fundação Perseu Abramo, 2002.

SOUSA, D.N. Reestruturação capitalista e trabalho: notas críticas acerca da economia solidária. Revista Katálysis, Florianópolis/SC, vol. 11, №. 01, pp.53-60, 2008.

SOUZA, M.L. "Território" da divergência (e da confusão): em torno das imprecisas fronteiras de um conceito fundamental. In: SAQUET, M.A.; SPOSITO, E.S. (Orgs). Territórios e territorialidades: teorias, processos e conflitos. São Paulo: Expressão Popular, 2009.

SPOSITO, E.S. Sobre o conceito de território: um exercício metodológico para a leitura da formação territorial do sudoeste do Paraná. In: RIBAS, A.D.; SPOSITO, E.S.; SAQUET, M.A. Território e Desenvolvimento: diferentes abordagens. Francisco Beltrão: Unioeste, 2004.

THOMAZ, R.C.C.; MARIANI, M.A.P.; MORETTI, E.C. (Orgs). O turismo e as territorialidades do campo e da cidade. Campo Grande/MS: Editora UFMS, 2012. 230p.

URRY, J. O olhar do turista: lazer e viagens nas sociedades contemporâneas. 3ª ed. São Paulo/SP: SESC/Studio Nobel, 2001.

VALVERDE, R.R.H.F. Transformação no conceito de território: competição e mobilidade na cidade. GEOUSP - Espaço e Tempo, São Paulo, №. 15, p. 119-126, 2004.

VERGARA, S.C. Projetos e Relatórios de Pesquisa em Administração. 6aㅡ ed. São Paulo: Editora Atlas, 2005.

VILPOUX, O.F.; OLIVEIRA, E.J. Instituições informais e governanças em arranjos produtivos locais. Revista de Economia Contemporânea, Rio de Janeiro/RJ, vol. 14, no. 01, p. 85-111, 2010.

WORLD TRAVEL AND TOURISM COUNCIL - WTCC. Travel \& Tourism: economic impact 2012 - World. London/UK: WTCC, 2012a.

WORLD TRAVEL AND TOURISM COUNCIL - WTCC. Travel \& Tourism: economic impact 2012 - Brazil. London/UK: WTCC, 2012b.

YIN, R.K. Estudo de caso: planejamento e métodos. 3aㅡ ed. Porto Alegre: Bookman, 2005.

\section{Notas:}

${ }^{1}$ Para maiores detalhes e referências, ver Arruda (2013).

${ }^{2}$ Entende-se que os EES perfazem as substantivações práticas das iniciativas de economia solidária, nos moldes expostos por Souza (2008). Para maiores detalhes, ver as discussões expressas em Arruda (2011). 
Milton Augusto Pasquotto Mariani: Universidade Federal de Mato Grosso do Sul, Campo Grande, MS, Brasil.

E-mail: miltmari@terra.com.br

Link para o currículo Lattes: http://lattes.cnpq.br/0935409945176042

Rosa Maria Fischer: Faculdade de Economia e Administração da Universidade de São Paulo, São Paulo, SP, Brasil.

E-mail: rfischer@usp.br

Link para o currículo Lattes: http://lattes.cnpq.br/9182438973940614

Data de submissão: 12 de fevereiro de 2014

Data de recebimento de correções: 05 de abril de 2014

Data do aceite: 06 de abril de 2014

Avaliado anonimamente 